\title{
A relaxed (rel) mutant of Streptomyces coelicolor A3(2) with a missing ribosomal protein lacks the ability to accumulate ppGpp, A-factor and prodigiosin
}

\author{
Kozo OCHI
}

Exploratory Research Laboratories, Fujisawa Pharmaceutical Co., Ltd, 5-2-3 Tokodai, Tsukuba, Ibaraki 300-26, Japan

(Received 23 February 1990; revised 29 May 1990; accepted 4 July 1990)

\begin{abstract}
A relaxed (rel) mutant was found among 70 thiopeptin-resistant isolates of Streptomyces coelicolor A3(2) which arose spontaneously. The ability of the rel mutant to accumulate ppGpp during Casamino acid deprivation was reduced 10-fold compared to the wild-type. Analysis of the ribosomal proteins by two-dimensional PAGE revealed that the mutant lacked a ribosomal protein, tentatively designated ST-L11. It was therefore classified as a relC mutant. The mutant was defective in producing A-factor and the pigmented antibiotic prodigiosin, in both liquid and agar cultures, but produced agarase normally. Production of actinorhodin, another pigmented antibiotic, was also abnormal; it appeared suddenly in agar cultures after $10 \mathrm{~d}$ incubation. Although aerial mycelium still formed, its appearance was markedly delayed. Whereas liquid cultures of the parent strain accumulated ppGpp, agar cultures accumulated only trace amounts. Instead, a substance characterized only as an unidentified HPLC peak accumulated intracellularly in the late growth phase, just before aerial mycelium formation and antibiotic production. This substance did not accumulate in mutant cells. It was found in S. lividans 66 and S. parvulus, but not in seven other Streptomyces species tested. The significance of these observations, and the relationship of the mutant to earlier rel isolates of Streptomyces is discussed.
\end{abstract}

\section{Introduction}

The genus Streptomyces is of considerable interest because of its complex life cycle, which includes aerial mycelium formation and sporulation, and because of its ability to produce numerous antibiotics and extracellular enzymes (for reviews, see Chater, 1984, 1989; Hopwood, 1988; Ochi, 1990b). Within this genus, Streptomyces coelicolor A3(2) is genetically the best-characterized species, and presents a well-developed system for analysing the molecular genetics of individual phenomena (reviewed by Hopwood, 1973, 1988). Recent studies include the transcriptional control of agarase (Buttner $e t$ al., 1988), rRNA synthesis (Baylis \& Bibb, 1988), sporulation genes (Mendez \& Chater, 1987; Guijarro et $a l ., 1988$ ) and antibiotic-induced proteins (Murakami et al., 1989). Since $S$. coelicolor A3(2) produces two pigmented antibiotics, actinorhodin and prodigiosin, in addition to two other antibiotics, this organism provides a useful system for studying the initiation of differentiation and secondary metabolism.

In micro-organisms, differentiation and secondary metabolism are usually simultaneous responses to nutrient limitation (for reviews, see Freese \& Heinze, 1984;
Chater, 1984, 1989). Investigating the mechanisms by which adverse environments may alter gene expression in these responses, I have observed that morphological differentiation of Bacillus subtilis and Streptomyces spp. is accompanied by a decrease in the GTP pool, whereas antibiotic production is linked to a more direct function of the rel gene - ppGpp accumulation (Ochi \& Ohsawa, 1984; Ochi, 1986a, $b, 1987 a, b, c, 1988)$. Recent genetic analyses of a $S$. griseus mutant demonstrated a link between the rel mutation and both inability to produce streptomycin and reduced ability to form aerial mycelium (Ochi, 1990a). In order to study the function of ppGpp using molecular genetics, I have isolated and characterized a rel mutant of $S$. coelicolor A3(2) which lacks the ability to accumulate ppGpp.

\section{Methods}

Chemicals. Thiopeptin (an analogue of thiostr epton) was a commercial product of my company. Guanosine 5'-monophosphate 3'diphosphate (pGpp), adenosine $5^{\prime}$-monophosphate $3^{\prime}$-diphosphate (pApp) and adenosine 5'-diphosphate $3^{\prime}$-diphosphate (ppApp) were generous gifts from A. Yoshimoto, Sanraku Co., Fujisawa, Japan. Adenosine $5^{\prime}$-tetraphosphate (Apppp), $P^{1}, P^{4}$-di(adenosine- $\left.5^{\prime}\right)$ tetraphosphate (AppppA), $P^{1}, P^{5}$-di(adenosine-5') pentaphosphate 
(ApppppA) and $P^{1}, P^{6}$-di(adenosine-5 $5^{\prime}$ hexaphosphate (AppppppA) were purchased from Sigma.

Strains and preparation of mutants. S. coelicolor A3(2), a wild-type prototrophic strain, was provided by D. A. Hopwood, John Innes Institute, Norwich, UK. The spontaneous thiopeptin-resistant mutants were obtained as resistant colonies, which developed $20 \mathrm{~d}$ after spreading spores on ISP medium 2 (Difco) supplemented with $20 \mu \mathrm{g}$ thiopeptin $\mathrm{ml}^{-1}$. Growth of the parent strain was suppressed almost completely at $5 \mu \mathrm{g}$ thiopeptin $\mathrm{ml}^{-1}$. The resistant clones were purified twice by single-colony isolation. This procedure appeared to be necessary to obtain stable resistant clones.

Growth conditions. All incubations were carried out at $30^{\circ} \mathrm{C} . \mathrm{CD}$ medium contained (per 1): glucose, $10 \mathrm{~g}$; ammonium sulphate, $3 \mathrm{~g}$; $\mathrm{NaCl}, 0.5 \mathrm{~g} ; \mathrm{KCl}, 50 \mathrm{mg} ; \mathrm{MgSO}_{4} .7 \mathrm{H}_{2} \mathrm{O}, 50 \mathrm{mg} ; \mathrm{ZnSO}_{4} .7 \mathrm{H}_{2} \mathrm{O}, 1 \mathrm{mg}$;

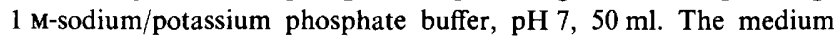
was sterilized at $120^{\circ} \mathrm{C}$ for $20 \mathrm{~min}$; glucose solutions were autoclaved separately. Soluble starch/polypeptone/yeast extract medium (SPY medium; Ochi, $1987 b$ ) used in this study contained $0.1 \%$, rather than $1 \%, \mathrm{MgSO}_{4}$. ISP medium 2 (Difco) contained (per 1): Bacto-yeast extract, $4 \mathrm{~g}$; Bacto-malt extract, $10 \mathrm{~g}$; Bacto-dextrose, $4 \mathrm{~g}$; Bacto-agar, $20 \mathrm{~g}$ (pH 7.3). ISP medium 3 (Difco) contained (per l) Bacto-oatmeal, $20 \mathrm{~g} ; \mathrm{FeSO}_{4} \cdot 7 \mathrm{H}_{2} \mathrm{O}, 1 \mathrm{mg} ; \mathrm{MnCl}_{2} .4 \mathrm{H}_{2} \mathrm{O}, 1 \mathrm{mg} ; \mathrm{ZnSO}_{4} \cdot 7 \mathrm{H}_{2} \mathrm{O}, 1 \mathrm{mg}$; Bacto-agar, $18 \mathrm{~g} \mathrm{(pH} \mathrm{7.2).} \mathrm{Plates} \mathrm{(diameter} 8.5 \mathrm{~cm}$ ) contained $20 \mathrm{ml}$ ISP medium 2 or ISP medium 3.

A monospore suspension, prepared as described previously (Ochi, $1987 b$ ), was used to inoculate SPY medium. After $2 \mathrm{~d}$ on a rotary shaker (230 r.p.m.), cells were washed twice with $100 \mathrm{ml}$ saline and suspended in their original volume of saline. This suspension $(2 \mathrm{ml})$ was then added to $50 \mathrm{ml} \mathrm{CD}$ medium (in a $250 \mathrm{ml}$ flask) supplemented with $3 \%(\mathrm{w} / \mathrm{v})$ vitamin-free Casamino acids (Difco) and cultured on a rotary shaker at 230 r.p.m. At the indicated times, cells were collected on a filter paper (Toyo Roshi no. $2,9 \mathrm{~cm}$ diameter) and rapidly transferred to $C D$ medium lacking Casamino acids, to cause amino acid depletion. Inoculation of the original medium with a monospore suspension was important, because pellet formation resulted in reduced ability (50$70 \%$ to accumulate ppGpp during Casamino acid deprivation. This may be caused by heterogeneous ageing of mycelia in the pellet, or by residual Casamino acids trapped inside the pellet.

Assay of nucleotide pools. The intracellular concentrations of ppGpp, pppGpp and other nucleotides were assayed by HPLC on a $25 \mathrm{~cm}$ Partisil PXS 10 SAX column (Whatman; void volume $3.02 \mathrm{ml}$ ) after extraction with $1 \mathrm{M}$-formic acid as previously described (Ochi, 1986b). The maximum error in HPLC measurements was $\pm 5 \%$, as determined by multiple HPLC analysis of the same sample.

In plate cultures, the intracellular nucleotide concentrations were determined as follows. A $0.1 \mathrm{ml}$ spore suspension (approx. $2 \times 10^{8}$ spores) was spread on cellophane (diameter $8 \mathrm{~cm}$; UV-sterilized) previously placed on the agar medium. At various times, the cellophane sheet with mycelia was removed, quickly weighed, and laid upsidedown in $1 \mathrm{ml}$ methanol in a plastic Petri dish (diameter $8.5 \mathrm{~cm}$ ); $10 \mathrm{ml}$ $1 \mathrm{M}$-formic acid was added immediately afterwards. The entire sampling procedure was completed within $10 \mathrm{~s}$. Due to the strong hydrophobicity of aerial mycelium, pre-treatment with methanol facilitated formic acid extraction; if it was omitted, extraction efficiency decreased by about $30 \%$. After $1 \mathrm{~h}$ in a cold-room, the extract was analysed by HPLC. The pool size was expressed as pmol or nmol nucleotides per mg dry weight of cells, using $1 \mathrm{~g}$ wet weight equivalent to $134 \mathrm{mg}$ dry weight, determined with cells grown on cellophane for $60 \mathrm{~h}$.

Determination of RNA synthesis. RNA synthesis after Casamino acid deprivation was determined by measuring $\left[2-{ }^{14} \mathrm{C}\right]$ uracil incorporation into acid-precipitable cell material as described by Ochi (1986b).
Determination of $\left[2-{ }^{14} \mathrm{C}\right]$ uracil uptake. Cells were grown for $10 \mathrm{~h}$ in CD medium supplemented with $3 \%$ Casamino acids. Before and after Casamino acid deprivation, $\left[2{ }^{14} \mathrm{C}\right]$ uracil was added to $20 \mu \mathrm{M}$ final concentration $\left(0.02 \mu \mathrm{Ci} \mathrm{ml}^{-1} ; 740 \mathrm{~Bq} \mathrm{ml}^{-1}\right)$ and incubation continued with shaking. Samples $(1 \mathrm{ml})$ were withdrawn at $2 \mathrm{~min}$ intervals for $6 \mathrm{~min}$, and the cells were collected on a membrane filter (Millipore, pore size $0.45 \mu \mathrm{m}$, diameter $25 \mathrm{~mm}$ ), washed with $5 \mathrm{ml} 0.1 \mathrm{M}-\mathrm{LiCl}$, and counted in a liquid scintillation counter, with Aquasol (New England Nuclear) as the scintillation fluid. Uptake was linear for at least 6 min.

Agarase determination. Agarase activity was determined by Gran's test as described by Hodgson \& Chater (1981). Since agarase production is subject to catabolic repression (Bibb et al., 1987), colonies were grown on $\mathrm{CD}$ medium in which glucose was replaced by $2 \%(\mathrm{w} / \mathrm{v})$ peptone. After 3 or $5 \mathrm{~d}$ incubation, $0.05 \mathrm{M}$-iodine in $0.12 \mathrm{M}$-KI was applied to the agar plate. Agarase activity was indicated by a clear halo around a colony.

A-factor assay. A-factor was assayed with a $S$. griseus mutant defective in its synthesis, as previously described (Ochi, 1987b).

Two-dimensional (2-D) PAGE. The method for 2-D PAGE, originally described by Kaltschmidt \& Wittman (1970), was as described in detail by Ochi (1989), as was the procedure for preparing ribosomes and total ribosomal protein. Electrophoretic separation was repeated two or three times for each preparation, to confirm the reproducibility of the results.

General reproducibility. The experiments shown in each Figure or Table were all repeated two or more times to confirm that the results were reproducible. Representative data are presented.

\section{Results}

\section{Accumulation of ppGpp by $S$. coelicolor A3(2)}

The ability of $S$. antibioticus to accumulate ppGpp is greatly affected by the culture conditions preceding nutritional shift-down (Ochi, 1987a). Therefore, initial experiments were done to define the conditions for maximal ppGpp formation by $S$. coelicolor. Cells were grown with varying amounts of Casamino acids for various times, and then transferred to Casamino-acidfree CD medium. The results are summarized in Table 1. Cells grown in nutritionally poor medium prior to Casamino acid deprivation accumulated less ppGpp. Further, maximum ppGpp synthesis was observed in cells grown for $10 \mathrm{~h}$ (mid-exponential phase) before transferral; accumulation was reduced to $50 \%$ or less in cells grown for $16 \mathrm{~h}$ (late exponential) or $24 \mathrm{~h}$ (postexponential). The greatest accumulation (650 pmol ppGpp per mg dry weight) occurred with cultures initially grown in CD medium with $3 \%$ Casamino acids for $10 \mathrm{~h}$.

\section{Isolation of a rel mutant}

Relaxed mutants with severely impaired ability to accumulate ppGpp have previously been isolated from several Streptomyces spp. as thiopeptin-resistant colonies 
Table 1. Effect of growth conditions on the ability of cells to accumulate ppGpp after Casamino acid deprivation

Cells of $S$. coelicolor A3(2) grown in chemically defined (CD) medium supplemented with various amounts of Casamino acids were harvested at the times indicated, and transferred to $C D$ medium without Casamino acids. After 15 min incubation with shaking, the cells were harvested and ppGpp was extracted. The ppGpp pool sizes just before the cells were deprived of Casamino acids were $15-45$ pmol (mg dry wt $)^{-1}$.

\begin{tabular}{lc}
\hline \hline $\begin{array}{l}\text { Growth conditions before } \\
\text { Casamino acid deprivation }\end{array}$ & $\begin{array}{c}\text { ppGpp accumulated after 15 min } \\
\text { Casamino acid deprivation } \\
\text { [pmol (mg dry wt) }\end{array}$ \\
\hline Grown for $14 \mathrm{~h}$ in $\mathrm{CD}$ & \\
medium with Casamino & \\
acids $(\mathrm{w} / \mathrm{v})$ : & 65 \\
$0.5 \%$ & 108 \\
$1 \%$ & 257 \\
$2 \%$ & 541 \\
$3 \%$ & 477 \\
$4 \%$ & \\
Grown in CD medium with & \\
$3 \%(\mathrm{w} / \mathrm{v})$ Casamino & \\
acids for: & 472 \\
$6 \mathrm{~h}$ & 650 \\
$10 \mathrm{~h}$ & 309 \\
$16 \mathrm{~h}$ & 210 \\
$24 \mathrm{~h}$ & \\
\hline \hline
\end{tabular}

(Ochi, 1986b, 1987a,b, 1988). A similar method was used in this study to isolate a relaxed mutant of $S$. coelicolor A3(2).

The conditions developed for maximum ppGpp accumulation were used to test 70 strains, randomly selected from thiopeptin-resistant isolates, for their ability to accumulate ppGpp. Only strain 63 produced substantially ( 10 -fold) less ppGpp than the parent strain after 15 min of Casamino acid deprivation.

In the parent strain, RNA synthesis, as measured by $\left[{ }^{14} \mathrm{C}\right]$ uracil incorporation into acid-precipitable cell material, was severely reduced on Casamino acid deprivation, but strain 63 continued RNA synthesis at an essentially unchanged rate (Fig. 1). Since in Escherichia coli and $B$. subtilis inhibition of uracil uptake can result not only from ppGpp accumulation (stringent response) but also from a decrease in GTP concentration, or both (Fast, 1978; Beaman et al., 1983), uracil uptake by $S$. coelicolor was also measured. Uracil uptake by cells of the parent strain decreased by $15 \%$ after Casamino acid deprivation, and by $27 \%$ in cells of strain 63. Because there was no marked differential change in UTP pool size between the parent and mutant strains in the initial 15 min of Casamino acid deprivation (Fig. 2), there was no need to allow for differences in the specific radioactivity of intracellular UTP. It can be concluded that mutant 63 exhibits a typical relaxed $(r e l)$ phenotype with respect to RNA synthesis.

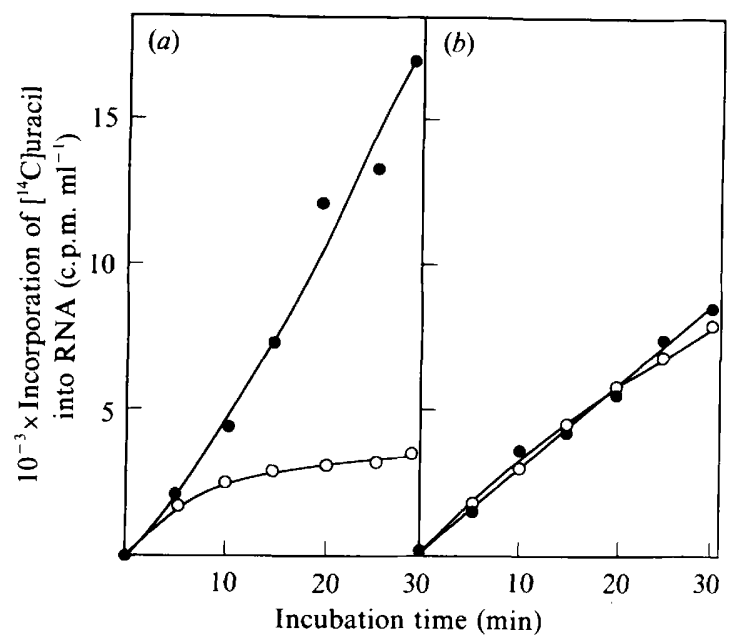

Fig. 1. RNA synthesis by (a) $S$. coelicolor A3(2) and (b) mutant 63 after deprivation of Casamino acids. Cells grown to mid-exponential phase ( $10 \mathrm{~h}$ for the parental strain and $16 \mathrm{~h}$ for the mutant) in $\mathrm{CD}$ medium plus $3 \%$ Casamino acids were collected and transferred, to give an $\mathrm{OD}_{600}$ of 2 , in $\mathrm{CD}$ medium containing $\left[2-{ }^{14} \mathrm{C}\right]$ uracil with $(\bullet)$ or without (O) Casamino acids, and incubated with shaking for $30 \mathrm{~min}$.

Changes in the intracellular nucleotide pool on Casamino acid deprivation were examined. Cells of the parent strain accumulated high levels of ppGpp immediately (Fig. 2). Accumulation of pppGpp was maximal at $10 \mathrm{~min}$, and was at most $20 \%$ of that of ppGpp (data not shown). The rel mutant accumulated far less ppGpp (and pppGpp, not shown) than the parent strain throughout $1 \mathrm{~h}$ incubation (Fig. 2). Unexpectedly, the decrease in the GTP pool of the parent strain was less extensive than that in the rel mutant. This result contrasts with observations on other Streptomyces spp. (Ochi, 1986b, $1987 a, c)$ and may be attributed to the much sharper decline in RNA synthesis in $S$. coelicolor on Casamino acid deprivation (Fig. 1); under such circumstances, nucleoside triphosphate utilization might be much reduced. I therefore measured ppGpp and GTP pool sizes during growth in normal conditions. Wild-type cells grown to post-exponential phase $(24-36 \mathrm{~h})$ in SPY medium maintained ppGpp levels about fourfold higher, and GTP levels much lower, than those in rel cells (Table 2). This result is consistent with those obtained for other Streptomyces spp.

\section{Characterization of the rel mutant}

Ribosomal proteins. The rel mutant lacked a ribosomal protein, as determined by 2-D PAGE (Fig. 3). No other ribosomal protein was missing or altered in electrophoretic mobility. (Several faint spots are not visible in both photographs, but were, however, present on both the gels; these are indicated with arrowheads.) No new spot that might represent an altered form of the protein was 


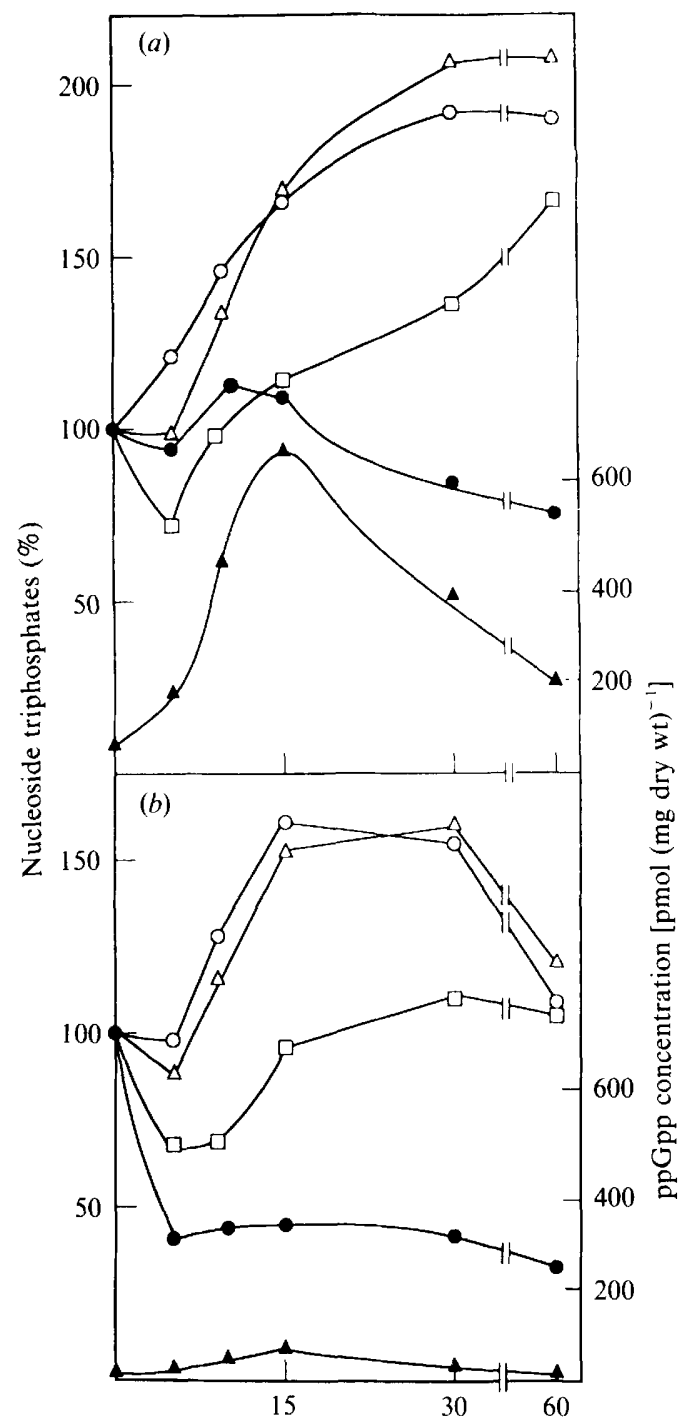

Time after Casamino acid deprivation (min)

Fig. 2. Changes in the intracellular pools of nucleoside triphosphates and ppGpp after deprivation of Casamino acids. Cells of strain A3(2) (a) or mutant $63(b)$, grown to mid-exponential phase in $\mathrm{CD}$ medium plus $3 \%$ Casamino acids as described in the legend to Fig. 1, were harvested and transferred to the same volume of fresh $\mathrm{CD}$ medium without Casamino acids and then incubated with shaking. Just before transfer, the nucleotide pool concentrations (mean of two samples) of GTP, ATP, UTP and CTP were 4.65, 12.0, 2.99 and $2 \cdot 11$ (strain A3(2)) and 5.06, 8.02, 2.70 and 2.05 (strain 63) $\mathrm{nmol}$ (mg dry wt) ${ }^{-1}$, respectively. •, GTP; $\Delta$, ppGpp; O, ATP; $\square$, UTP; $\triangle$, CTP.

seen on the gel, although it might have been hidden by another protein spot. Strain 63 can thus be classified as a relC mutant, and the missing protein was tentatively designated ST-L11 by analogy with $E$. coli and B. subtilis mutants which lack ribosomal proteins L11 and BS-L11, respectively (Friesen et al., 1974; Smith et al., 1978, 1980).
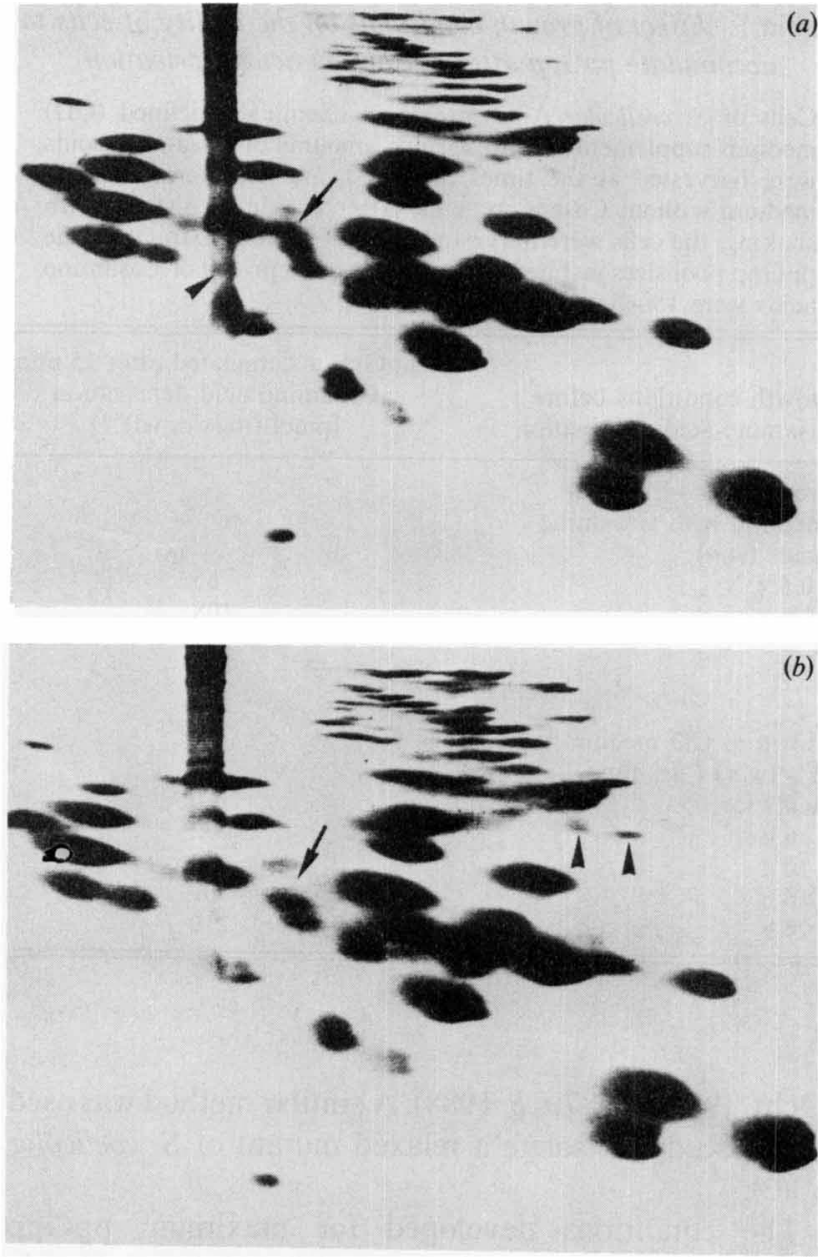

Fig. 3. 2-D PAGE of total ribosomal proteins. The gel system was based upon that of Kaltschmidt \& Wittmann (1970). (a) $S$. coelicolor A3(2); (b) mutant 63. The arrows indicate a protein spot (ST-L11), which was absent in the mutant. Several faint spots, indicated by arrowheads, are not visible in both photographs, but were present in both the original gels.

Table 2. Intracellular nucleotide pools of cells grown in $S P Y$ medium

Cells of the parent strain or mutant 63 were grown in SPY medium with shaking. At the indicated times, the cells were harvested, extracted and assayed for intracellular nucleotides.

\begin{tabular}{lcccc}
\hline \hline & & \multicolumn{3}{c}{$\begin{array}{c}\text { Nucleotide concentration } \\
\text { [pmol (mg dry wt) }\end{array}$} \\
\cline { 3 - 5 } Strain & $\begin{array}{c}\text { Time } \\
\text { (h) }\end{array}$ & ppGpp & GTP & ATP \\
\hline Parent $\left(\mathrm{rel}^{+}\right)$ & 24 & 103 & 945 & 4790 \\
& 36 & 46 & 820 & 4660 \\
$63(\mathrm{rel})$ & 24 & 28 & 1780 & 6440 \\
& 36 & 26 & 1470 & 4800 \\
\hline \hline
\end{tabular}


Antibiotic resistance. The relC mutant was resistant to $30 \mu \mathrm{g}$ thiopeptin $\mathrm{ml}^{-1}$ after $4 \mathrm{~d}$ incubation on ISP medium 2; the parent strain was resistant only to $2 \mu \mathrm{g} \mathrm{ml}^{-1}$. However, although the parent strain grew normally in the presence of $10 \mu \mathrm{g}$ erythromycin $\mathrm{ml}^{-1}$, growth of the mutant was completely abolished by $0 \cdot 1 \mu \mathrm{g} \mathrm{ml}^{-1}$. Growth of mutant cells was also almost completely arrested at $40^{\circ} \mathrm{C}$, although the parent strain grew normally at this temperature.

Secondary metabolism. The relC mutant was strikingly deficient in production of the pigmented antibiotics prodigiosin and actinorhodin. The parent strain $S$. coelicolor A3(2) synthesized these compounds after 2-3 d incubation on ISP medium 2 or Hopwood's medium (Hopwood, 1967), but the mutant failed to produce either in $10 \mathrm{~d}$ incubation. Cultures were not examined for production of methylenomycin. However, after $10 \mathrm{~d}$ incubation, mutant cells suddenly produced a blue pigment identified by TLC as actinorhodin. The amount was about 20 -fold greater than that formed by the parent strain, and no undecylprodigiosin was detected. Although intriguing, the mechanism of this abnormal production was not studied further.

A-factor $\quad(2 S$-isocapryloyl-3S-hydroxymethyl- $\gamma$-butyrolactone) is an autoregulating factor produced by $S$. griseus, controlling both differentiation and streptomycin production. Mutants unable to synthesize A-factor (afs) are defective in these processes (Horinouchi et al., 1983; Ochi, 1987b). Previously isolated relC mutants of $S$. griseus were able to synthesize A-factor normally (Ochi, 1987b), but the $S$. coelicolor relC mutant was not. The parent strain produced A-factor at a lower level (5$10 \mathrm{ng} \mathrm{m}^{-1}$ ), detectable after $2 \mathrm{~d}$ incubation in liquid or solid ISP medium 2, with or without $100 \mathrm{~mm}$-phosphate buffer $(\mathrm{pH} 7)$, but the mutant produced $<1 \mathrm{ng} \mathrm{ml}^{-1}$ under these conditions. Addition of exogenous A-factor to a final concentration of $0 \cdot 01-1 \mu \mathrm{g} \mathrm{ml}^{-1} \mathrm{did}$ not restore antibiotic production in the mutant.

Aerial mycelium formation. The relC mutant retained the ability to form aerial mycelium on ISP medium 2, but the onset of formation was delayed by $5 \mathrm{~d}$, and less was produced than in the parent strain. The addition of Afactor with or without $0 \cdot 1-2 \mathrm{~mm}$-decoyinine to cultures did not restore wild-type mycelium formation (data not shown).

Agarase production. S. coelicolor is distinctive in its ability to utilize agarose as a sole carbon source by excreting agarase into the medium (Hodgson \& Chater, 1981; Bibb et al., 1987). Both parent and mutant strains produced agarase normally, as determined by Gran's test, producing $3 \mathrm{~mm}$ diameter haloes on an agar plate.

\section{Correlation between the relC mutation and the altered phenotype}

Twenty isolates, varying in thiopeptin resistance from 15 to $80 \mu \mathrm{g} \mathrm{ml}^{-1}$, were tested for pigmented antibiotic production, aerial mycelium formation, erythromycin sensitivity and temperature sensitivity. All exhibited the normal parental phenotype for most of these characteristics, although a few exhibited a slight reduction in antibiotic productivity, or a slight increase in temperature sensitivity, or both. The ribosomal proteins of five thiopeptin-resistant isolates were also analysed by 2DPAGE; no difference was observed between the tested isolates and the parent strain, and the ST-L11 protein was at the normal location in each case. These results suggest that the abnormal behaviour of strain 63 results from the putative relC mutation.

No phenotypic reversion of the relC mutant was observed by examining for ability to form pigmented antibiotics or loss of erythromycin sensitivity.

\section{Changes in the nucleotide pool during growth on agar media}

Unlike $S$. griseus, $S$. coelicolor produces aerial mycelium and spores only on agar medium. Changes in the nucleotide pool during growth on ISP medium 2 were examined using the cellophane-sheet technique. The results may not accurately reflect the physiology of cells growing on the medium without the limitations in permeability due to the cellophane; however, the parent strain produced as much antibiotic and aerial mycelium with the cellophane as without it.

The intracellular pool size of GTP was high in early growth phase, but abruptly decreased at mid-growth phase in both parent and mutant strains (Fig. 4). This decrease was more pronounced, though not greatly so, in the parent strain; near the onset of mycelium formation $(50-70 \mathrm{~h})$, the lowest pool size measured was only onefourth that observed in the mutant. The ppGpp pool size in the parent strain (5-10 pmol per mg dry weight) was well below that measured in liquid culture (about 100 pmol per mg dry weight; Table 2) throughout $90 \mathrm{~h}$ incubation. In the relC mutant, ppGpp pool size was 25 pmol per mg dry weight. pppGpp was undetectable ( $<5$ pmol per mg dry weight) in both strains.

Analysis of nucleotide pools by HPLC (Fig. 5) indicated that the parent strain (but not the mutant) accumulated an unknown substance (US) intracellularly in the late growth phase of cultures on agar media (Fig. 4). Cultures were not tested for extracellular accumulation. The UV absorption spectrum of US in phosphate buffer at pH 5.4 (inset in Fig. 5) displayed a maximum at $255 \mathrm{~nm}$ and resembled that of ATP. US also accumu- 


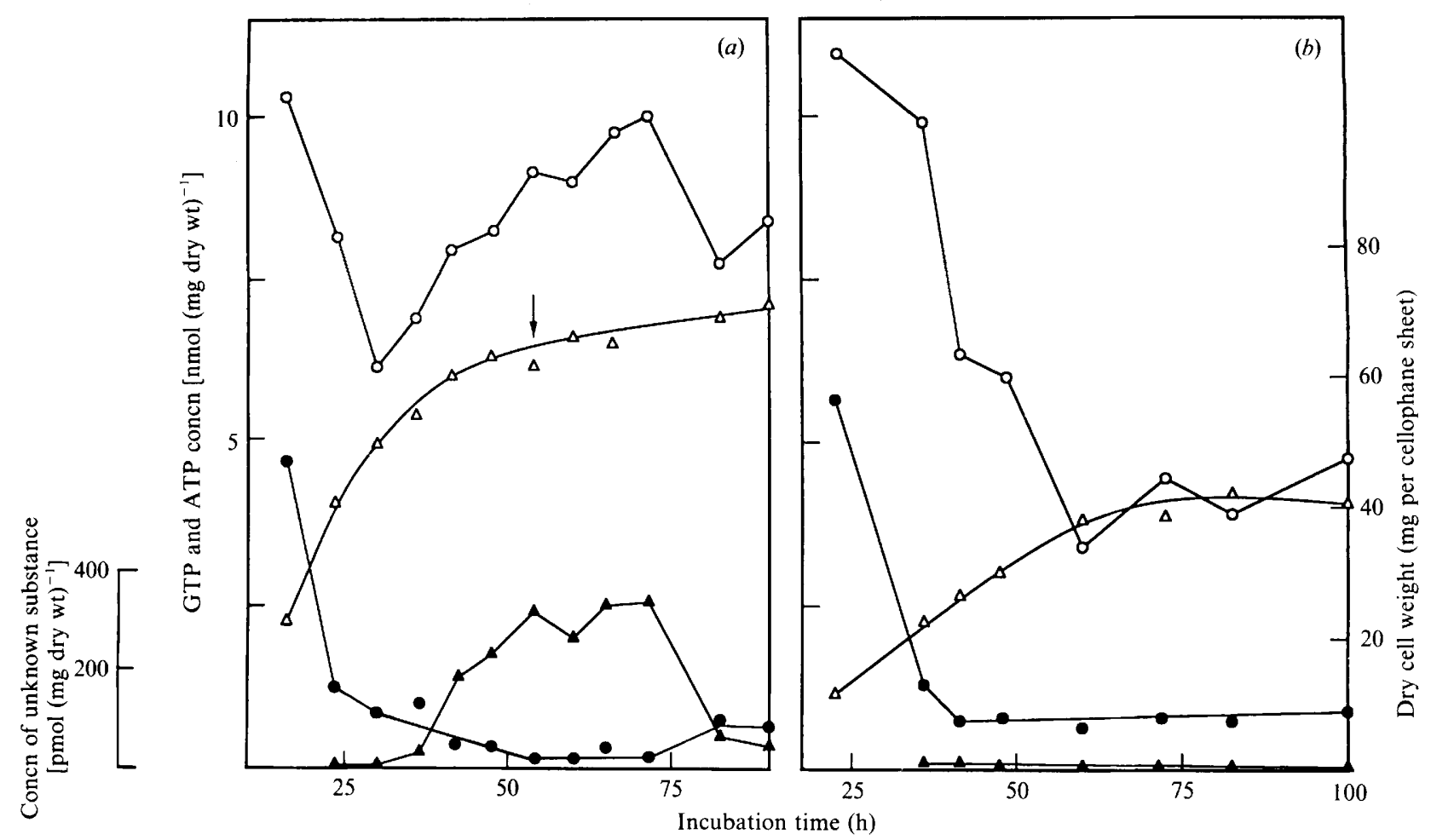

Fig. 4. Changes in the intracellular pools of GTP, ATP and an unknown substance in $(a)$ strain A3(2) and $(b)$ mutant 63 during growth on agar (ISP medium 2) covered with a cellophane sheet. The concentration of the unknown substance was calculated tentatively using the molar absorption coefficient of ATP. The arrow indicates the time at which antibiotic production and aerial mycelium formation began. $\bullet$, GTP; O, ATP; $\Delta$, unknown substance; $\triangle$, dry cell wt per cellophane sheet.

lated intracellularly in the parent strain in liquid cultures, but was detected only during a period of about $6 \mathrm{~h}$, between 24 and $30 \mathrm{~h}$ incubation.

In eukaryotic cells, some adenosine polyphosphate species may be signal nucleotides (reviewed by Jakubowski, 1986; Plateau et al., 1989). However, US differed in HPLC retention time from known adenosine polyphosphates (AppppA, ApppppA, AppppppA, pApp, ppApp) (Fig. 5).

Finally, nine other Streptomyces spp. were tested for US accumulation. Since prolonged accumulation of US was only detected in agar cultures, cells were grown on agar plates of ISP medium 2 or ISP medium 3 for $4 \mathrm{~d}$, and assayed daily for US, using HPLC. S. lividans 66 and $S$. parvulus ATCC 12434 accumulated as much US as $S$. coelicolor, but $S$. antibioticus 3720 , S. lavendulae MA406A-1, S. griseus IFO 13189, S. griseoflavus FERM 1805, S. hygroscopicus IFO 13472, S. venezuelae IFO 13096 and $S$. violaceus IFO 13103 did not accumulate detectable amounts.

\section{Discussion}

Thiopeptin-resistant rel mutants have been isolated previously from various Streptomyces spp., e.g. $S$. antibioticus, $S$. lavendulae, $S$. griseus and $S$. griseoflavus. These were all demonstrated to have an altered or missing ribosomal protein, designated ST-L11. I have summarized their properties (Ochi, 1990a) with regard to ppGpp accumulation, RNA synthesis, antibiotic production, temperature sensitivity and drug sensitivity. More specifically, these properties comprise: (1) about 10 -fold reduction in ppGpp accumulation during Casamino acid deprivation; (2) continued RNA synthesis during Casamino acid deprivation; (3) markedly reduced antibiotic production; (4) markedly late formation of aerial mycelium; (5) increased sensitivity to high temperatures (except $S$. antibioticus relC mutant 49); (6) increased sensitivity to erythromycin (except $S$. antibioticus relC mutant 49 ), but a 10 - to 15 -fold increase in thiopeptin resistance; (7) a somewhat reduced growth rate, especially in CD medium. $S$. coelicolor mutant 63 shares these properties. The 2-D PAGE gel positions of the ribosomal proteins which were altered or missing in these relC mutants were all similar, namely $7-11 \mathrm{~mm}$ from the origin in the first dimension, and $35-40 \mathrm{~mm}$ in the second (Ochi, 1990a ; this study). Although considerable electrophoretic variability exists among the ribosomal protein patterns of different Streptomyces spp. (Ochi, 1989), the above evidence suggests that the 


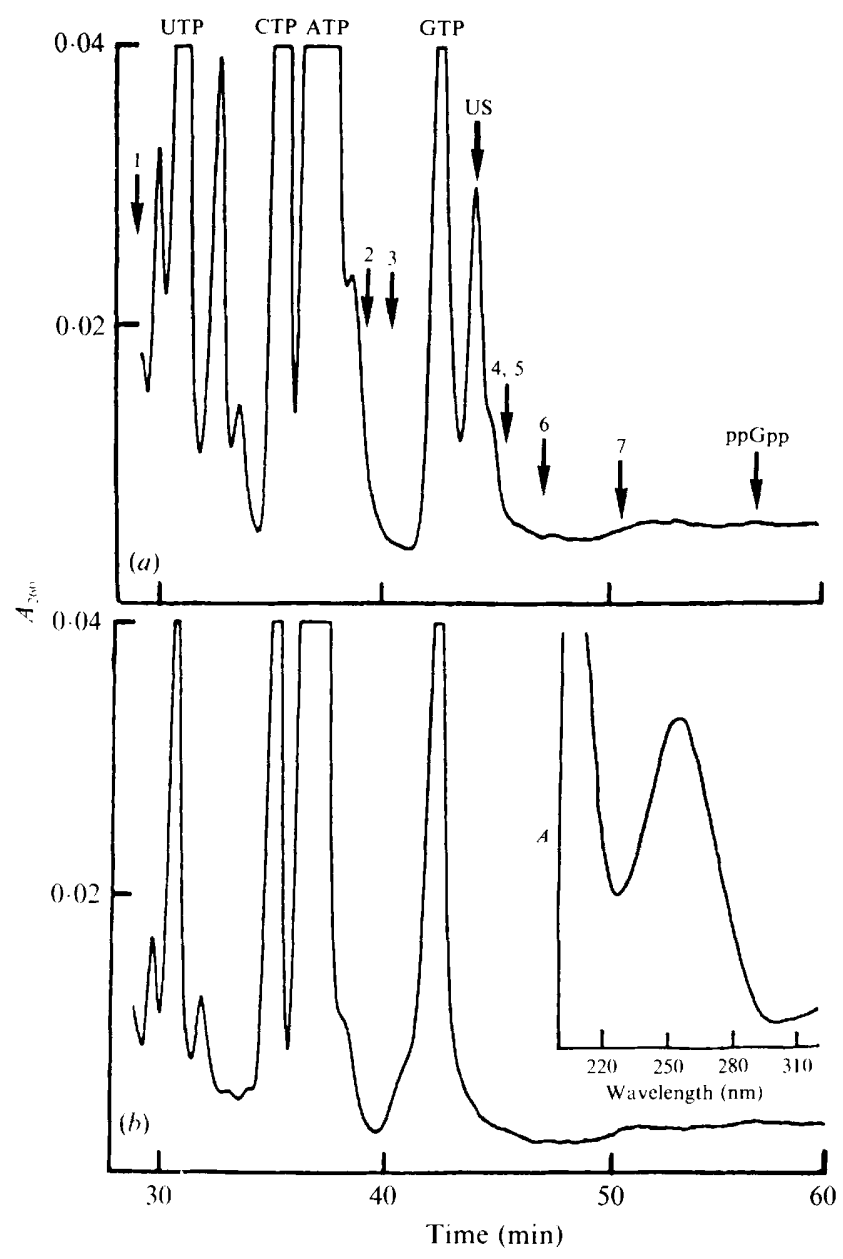

Fig. 5. Elution profile from HPLC of nucleotides extracted from cells of (a) strain $\mathrm{A} 3(2)$ or $(b)$ mutant 63 grown on agar covered with a cellophane sheet for $42 \mathrm{~h}(\mathrm{~A} 3(2))$ or $60 \mathrm{~h}$ (mutant 63). The samples injected were extracted from $6.5-7.7 \mathrm{mg}$ cell dry wt. The unknown substance is labelled US. The numbered arrows indicate the retention times for: 1, AppppA ; 2, ApppppA ; 3, pApp ; 4, AppppppA ; 5, pGpp; 6, Apppp; 7, ppApp. The inset shows a UV spectrum of US in phosphate buffer at pH 5.4.

missing protein confers the observed phenotype. It is therefore referred to in all species as ST-L11; however, its identity as 'L11-like' has not been proven, but suggested by analogy with ribosomal protein functions in E. coli and B. subtilis. Confirmation requires demonstration of immunochemical or functional homology with the E. coli $\mathrm{L} 11$ protein.

One goal in studying the mechanism of morphological and physiological differentiation is to identify the biochemical effectors responsible. All Streptomyces relC mutants so far isolated are severely impaired in the production of an antibiotic (Ochi, 1990a; this study). In E. coli, ppGpp can affect gene expression by altering the selectivity of RNA polymerase in vivo and in vitro (Kajitani \& Ishihama, 1984; Baracchini et al., 1988). One can envisage a model in which ppGpp could trigger antibiotic production in Streptomyces spp. in response to physiological conditions. However, although the phenotypic properties discussed have been tentatively related to the relC mutation, including the failure to produce prodigiosin, genetic analysis is required before the altered phenotype can be unambiguously attributed to the relC lesion. The availability of genetic markers and the high frequency of genetic recombination in $S$. coelicolor A3(2) (Hopwood, 1973) will be helpful in such a study. Further analysis at the molecular level is needed to establish a causal link between ppGpp accumulation and the onset of prodigiosin or actinorhodin production.

A striking difference between relC mutants of $S$. griseus and those of $S$. coelicolor is that the former produce A-factor normally, but the latter produce none. A-factor plays an important role in $S$. griseus, controlling differentiation and streptomycin production. In $S$. coelicolor, however, A-factor plays no such role; its synthesis and those of antibiotics are controlled at the same level in a hierarchical regulatory cascade (Horinouchi et al., 1983; Hopwood, 1988), implying that it is a simple secondary metabolite in this organism. The nonproduction of both A-factor and antibiotics in the $S$. coelicolor relC mutant is consistent with this view.

In agar cultures, several unexpected results were obtained. Firstly, the relC mutant was delayed in the onset of aerial mycelium formation, despite a timely reduction in GTP pool size at the mid-growth phase (Fig. 4). Unless the different minimum pool sizes observed between the parent and mutant strains are significant, additional conditions may have to be met before the GTP decrease can trigger aerial mycelium formation. This possibility is supported by the different sporulation response of $S$. coelicolor A3(2) as compared with $S$. griseus, S. griseoflavus and S. lavendulae MA406-A-1. In contrast with observations of the latter three species (Ochi, 1986a, 1987b, Ochi et al., 1988), in S. coelicolor the suppressive effect of $2-4 \%$ Casamino acids on aerial mycelium formation could not be reversed by decoyinine, a specific inhibitor of GMP synthetase, at any of the concentrations tested (unpublished results). Mutant 63 may be unable to achieve the required physiological conditions due to the relC lesion. Since A-factor did not restore normal mycelium formation, its presence appears not to play a determining role. It is also noteworthy that Granozzi et al. (1990) reported a transitory cessation of macromolecular synthesis (particularly of RNA) just before aerial mycelium was formed in $S$. coelicolor A3(2).

Secondly, although mutant 63 produced no prodigiosin, it produced large amounts of actinorhodin after $10 \mathrm{~d}$ incubation on agar. No explanation can be offered for this at present, but it implies that different mechanisms initiate production of the two antibiotics. 
Thirdly, the parent strain accumulated only trace amounts of ppGpp in agar cultures, but accumulated an unidentified substance (US), whose UV spectrum resembled that of ATP, just before differentiation. The mechanism of US synthesis evidently differs from that of ppGpp, because US did not accumulate during Casamino acid deprivation. The relC mutant did not accumulate US, implying that US synthesis may be controlled by ppGpp. Whether US acts as a signal molecule, together with or instead of ppGpp, in initiating antibiotic production by some Streptomyces spp. merits further investigation.

\section{References}

Baracchini, E., Glass, R. \& Bremer, H. (1988). Studies in vivo on Escherichia coli RNA polymerase mutants altered in the stringent response. Molecular and General Genetics 213, 379-387.

BAYLIS, H. A. \& BibB, M. J. (1988). Transcriptional analysis of the $16 \mathrm{~S}$ rRNA gene of the $r r n D$ gene set of Streptomyces coelicolor A3(2). Molecular Microbiology 2, 569-579.

Beaman, T. C., Hitchins, A. D., Ochi, K., Vasantha, N., Endo, T. \& FreEse, E. (1983). Specificity and control of uptake of purines and other compounds in Bacillus subtilis. Journal of Bacteriology 156, $1107-1117$.

BibB, M. J., Jones, G. H., Joseph, R., BUtTNER, M. J. \& WARD, J. M. (1987). The agarase gene $(\operatorname{dag} A)$ of Streptomyces coelicolor A3(2): affinity purification and characterization of the cloned gene product. Journal of General Microbiology 133, 2089-2096.

Buttner, M. J., SMith, A. M. \& BiBB, M. J. (1988). At least three RNA polymerase holoenzymes direct transcription of the agarase gene (dagA) of Streptomyces coelicolor A3(2). Cell 52, 599-607.

CHATER, K. F. (1984). Morphological and physiological differentiation in Streptomyces. In Microbial Development, pp. 89-116. Edited by R Losick \& L. Shapiro. Cold Spring Harbor, NY: Cold Spring Harbor Laboratory.

Chater, K. F. (1989). Sporulation in Streptomyces. In Regulation of Procaryotic Development, pp. 277-299. Edited by I. Smith, R. A. Slepecky \& P. Setlow. Washington, DC: American Society for Microbiology.

FAST, R. (1978). Isolation of Escherichia coli mutants with changed regulation of uracil uptake. Journal of Bacteriology 136, 839-843.

Freese, E. \& Heinze, J. (1984). Metabolic and genetic control of bacterial sporulation. In The Bacterial Spore, vol. 2, pp. 101-172. Edited by A. Hurst, G. W. Gould \& J. Dring. London: Academic Press.

Friesen, J. D., FiIl, N. P., Parker, J. M. \& Haseltine, W. A. (1974). A new relaxed mutant of Escherichia coli with an altered $50 \mathrm{~S}$ ribosomal subunit. Proceedings of the National Academy of Sciences of the United States of America 71, 3465-3469.

Granozzi, C., Billetta, R., Passantino, R., Sollazzo, M. \& Puglia, A. M. (1990). A breakdown in macromolecular synthesis preceding differentiation in Streptomyces coelicolor A3(2). Journal of General Microbiology 136, 713-716.

Guijarro, J., Santamaria, R., Schauer, A. \& Losick, R. (1988). Promoter determining the timing and spatial localization of transcription of a cloned Streptomyces coelicolor gene encoding a spore-associated polypeptide. Journal of Bacteriology 170, 18951901

Hodgson, D. A. \& Chater, K. F. (1981). A chromosomal locus controlling extracellular agarase production by Streptomyces coelicolor A3(2), and its inactivation by chromosomal integration of plasmid SCPI. Journal of General Microbiology 124, 339-348.

HoPwOOD, D. A. (1967). Genetic analysis and genome structure in Streptomyces coelicolor. Bacteriological Reviews 31, 373-403.

HoPWOOD, D. A. (1973). Advances in Streptomyces coelicolor genetics. Bacteriological Reviews 37, 371-405.
HopwOoD, D. A. (1988). Towards an understanding of gene switching in Streptomyces, the basis of sporulation and antibiotic production. Proceedings of the Royal Society B235, 121-138.

HorinouChI, S., HaRA, O. \& BEPPU, T. (1983). Cloning of a pleiotropic gene that positively controls biosynthesis of A-factor, actinorhodin, and prodigiosin in Streptomyces coelicolor A3(2) and Streptomyces lividans. Journal of Bacteriology 155, 1238-1248.

JAKUBOWSKI, H. (1986). Sporulation of the yeast Saccharomyces cerevisiae is accompanied by synthesis of adenosine 5'-tetraphosphate and adenosine 5'-pentaphosphate. Proceedings of the National Academy of Sciences of the United States of America 83, 2378-2382.

KaJitani, M. \& Ishihama, A. (1984). Promoter selectivity of Escherichia coli RNA polymerase. Differential stringent control of the multiple promoters from ribosomal RNA and protein operons. Journal of Biological Chemistry 259, 1951-1957.

Kaltschmidt, E. \& WittmanN, H. G. (1970). Ribosomal proteins. VII. Two-dimensional polyacrylamide gel electrophoresis for fingerprinting of ribosomal proteins. Analytical Biochemistry 36, 401-412.

Mendez, C. \& Chater, K. F. (1987). Cloning of whiG, a gene critical for sporulation of Streptomyces coelicolor A3(2). Journal of Bacteriology 169, 5715-5720.

Murakami, T., Holt, T. G. \& Thompson, C. J. (1989). Thiostreptoninduced gene expression in Streptomyces lividans. Journal of Bacteriology 171, 1459-1466.

OCHI, K. (1986a). A decrease in GTP content is associated with aerial mycelium formation in Streptomyces MA406-A-1. Journal of General Microbiology 132, 299-305.

$\mathrm{OCH}, \mathrm{K} .(1986 b)$. Occurrence of the stringent response in Streptomyces sp. and its significance for the initiation of morphological and physiological differentiation. Journal of General Microbiology 132, $2621-2631$

OCHI, K. (1987a). A rel mutation abolishes the enzyme induction needed for actinomycin synthesis by Streptomyces antibioticus. Agricultural and Biological Chemistry 51, 829-835.

OCHI, K. $(1987 b)$. Metabolic initiation of differentiation and secondary metabolism by Streptomyces griseus: significance of the stringent response (ppGpp) and GTP content in relation to A-factor. Journal of Bacteriology 169, 3608-3616.

OCHI, K. $(1987 c)$. Changes in nucleotide pools during sporulation of Streptomyces griseus in submerged culture. Journal of General Microbiology 133, 2787-2795

OCHI, K. (1988). Nucleotide pools and stringent response in regulation of Streptomyces differentiation. In Biology of Actinomycetes, '88, pp. 330-337. Edited by Y. Okami, T. Beppu \& H. Ogawara. Tokyo: Japan Scientific Societies Press.

OCHI, K. (1989). Heterogeneity of ribosomal proteins among Streptomyces species and its application to identification. Journal of General Microbiology 135, 2635-2642.

OCHI, K. (1990a). Streptomyces relC mutants with an altered ribosomal protein ST-LIl and genetic analysis of a Streptomyces griseus relC mutant. Journal of Bacteriology 172, 4008-4016.

OCHI, K. (1990b). Streptomyces griseus as an excellent object for studying microbial differentiation. Actinomycetologica 4, 23-30.

OCHI, K. \& OHSAWA, S. (1984). Initiation of antibiotic production by the stringent response of Bacillus subtilis Marburg. Journal of General Microbiology 130, 2473-2482.

Ochi, K., Tsurumi, Y., Shigematsu, N., Iwami, M., Umehara, K. \& OKunara, M. (1988). Physiological analysis of bicozamycin highproducing Streptomyces griseoflavus used at industrial level. Journal of Antibiotics 41, 1106-1115.

Plateau, P., Fromant, M., Schmitter, J. M., Buhler, J. M. \& BLANQUET, S. (1989). Isolation, characterization, and inactivation of the $A P A]$ gene encoding yeast diadenosine $5^{\prime}, 5^{\prime \prime \prime}-\mathrm{P}^{1}, \mathrm{P}^{4}$-tetraphosphate phosphorylase. Journal of Bacteriology 171, 6437-6445.

Smith, I., Paress, P. \& PestKa, S. (1978). Thiostrepton-resistant mutants exhibited relaxed synthesis of RNA. Proceedings of the National Academy of Sciences of the United States of America 75, 5993-5997.

Smith, I., Paress, P., Cabane, K. \& Dubnau, E. (1980). Genetics and physiology of the rel system of Bacillus subtilis. Molecular and General Genetics 178, 271-279. 